\title{
Trigonal Nitrogen Activates High-Brightness Chemiluminescent
}

\section{Carbon Nanodots}

Cheng-Long Shen, ${ }^{\dagger}$ Qing Lou, ${ }^{\dagger},+*$ Chao-Fan Lv, ${ }^{\dagger}$ Guang-Song Zheng, ${ }^{\dagger}$ Jin-Hao Zang, ${ }^{\dagger}$ Tian-Ci Jiang, ${ }^{\S}$ Zhe Cheng, ${ }^{\S}$ Kai-Kai Liu, ${ }^{\dagger}$ Chun-Yao Niu,${ }^{\dagger} *$ Lin Dong, ${ }^{\dagger}$ Chong-Xin Shan ${ }^{\dagger} * *$

${ }^{\dagger}$ Henan Key Laboratory of Diamond Optoelectronic Materials and Devices, Key Laboratory of Material Physics, Ministry of Education, School of Physics and Microelectronics, Zhengzhou University, Zhengzhou, 450052, China

$\$$ Provincial and Ministerial Co-construction of Collaborative Innovation Center for Resource Materials, Zhengzhou University, Zhengzhou, 450001, China

$\S$ Department of Respiratory and Critical Care Medicine, The First Affiliated Hospital of Zhengzhou University, Zhengzhou, 450052, China

\section{EXPERIMENTAL SECTION}

\section{Materials.}

Bis(2,4,5-trichloro-6-carbopentoxyphenyl) peroxalate (CPPO, 98\%), citric acid $\left(\mathrm{C}_{6} \mathrm{H}_{8} \mathrm{O}_{7}, 99.9 \%\right)$, urea $\left(\mathrm{CON}_{2} \mathrm{H}_{4}, 99.9 \%\right)$, Rhodamine $\mathrm{B}\left(\mathrm{C}_{28} \mathrm{H}_{31} \mathrm{ClN}_{2} \mathrm{O}_{3}, 99 \%\right)$ were purchased by Aladdin Reagent Co., Ltd (Shanghai, P. R. China). Ethanol (99.9\%), ethyl acetate (99.9\%), hydrogen peroxide $\left(\mathrm{H}_{2} \mathrm{O}_{2}, 30 \%\right)$, dibutyl phthalate (DBP, 99.9\%) and tert-butanol $\left(\mathrm{C}_{4} \mathrm{H}_{10} \mathrm{O}, 99.9 \%\right)$ were purchased from Sinopharm Chemical Reagent Co., Ltd (Shanghai, P. R. China). The commercial CPPO was purchased in Taobao (Mingling, 98\%). The chemicals reagents were analytical grade and used as received without further purification.

\section{Characterization.}

The surface morphology of the three CDs was characterized by a field emission transmission electron microscope (HRTEM, JEOL JSM-IT100). The X-ray diffractometer (Panalytical X' Pert Pro) using $\mathrm{Cu} \mathrm{k}_{\alpha}$ as the irradiation source was used 
to obtain the XRD patterns. The Fourier transform infrared spectra (FT-IR) were recorded on a Bio-Rad Excalibur spectrometer (Bruker vector 22). X-ray photoelectron spectroscopy (XPS) was measured on a Kratos AXIS HIS 165 spectrometer with a monochromatized Al KR X-ray source $(1486.7 \mathrm{eV})$.

\section{Experiments.}

Synthesis and purification of CDs. The chemiluminescent (CL) CDs were synthesized with different weight ratio of urea and citric acid by microwave-assist pyrolysis. Actually, $0.8 \mathrm{~g}$ citric acid with $0,0.1,0.4,0.8,1.6$ and $2.4 \mathrm{~g}$ urea were dissolved in 10 $\mathrm{ml}$ deionized water and the solution was transferred to microwave oven and heated for $15 \mathrm{~min}$. Then, the obtained brown products were dissolved in $100 \mathrm{~mL}$ water under the help of ultrasonic. After filtering through filter paper, the obtained clear solution was freeze-dried. To obtain the efficient CL CDs, the obtained CD powders were further purified. Actually, the original $0.5-\mathrm{g}$ CD powders were dispersed in $50 \mathrm{~mL}$ ethanol with ultrasonic and then filtered through filter paper to remove the precipitate. The obtained clear CDs ethanol solution was dried through rotation-evaporation met for further characterization.

The measurement of $P L$ and $C L$. The UV-Vis absorption spectrum of the CDs in ethanol solution was collected using a Hitachi UVH-4150 spectrometer. The fluorescence excitation-emission matrices of related CDs in ethanol solution were measure with a Hitachi F-7000 spectrophotometer. The fluorescence decay curves of the samples were measured by Horiba FL-322 using a $370 \mathrm{~nm}$ Nano-LED monitoring the related emission, respectively. The CL spectrum was collected by the spectrophotometer (Hitachi F-7000) with the lamp off and the wavelength-time matrix was recorded after injecting the CDs into the mixture of $\mathrm{CPPO}$ and $\mathrm{H}_{2} \mathrm{O}_{2}$. The luminescence intensity was recorded by a system comprising a photometer (Minolta Luminance Meter LS-110).

Degree of crystalline (DOC): In this work, the DOC of the H-NCDs can be calculated as follows:

$\mathrm{DOC}=\frac{\text { Area }(\text { crystalline })}{\text { Area(crystalline })+ \text { Area }(\text { amorphous })}=\frac{0.07127+0.32447}{0.07127+0.32447+4.53148}=0.2029542$

Hence, the DOC of H-NCDs is around $20 \%$.

Synthesis of CL illuminator. In this work, the CD-based CL illuminator is prepared as follows. Commercially available CPPO $(1.5 \mathrm{~g})$ was dispersed into $10-\mathrm{mL}$ DBP to 
form CPPO saturated solution. Then $10-\mathrm{mL}$ different concentration H-NCDs solution $\left(0.3,0.6,0.9,1.2,1.5,1.8,2.1,2.4,2.7\right.$ and $\left.3.0 \mathrm{mg} \mathrm{mL}^{-1}\right)$ were added into the CPPO saturated solution. After adding $10-\mathrm{mL} \mathrm{H}_{2} \mathrm{O}_{2}$ tert-butanol solution $(1 \mathrm{M})$, bright CL can be observed by naked-eyes. On the condition, the CL photo was collected by a Nikon D600 digital camera and the luminance of the CD-based illumination was recorded by a system comprising a photometer (Minolta Luminance Meter LS-110) during the continuous CL emission.

The measurement of CL QYs. The CL QYs of CDs were measured using lucigenin with $\mathrm{H}_{2} \mathrm{O}_{2}$ as oxidant with a known QY of $11.3 \times 10^{-3}$ einsteins $\mathrm{mol}^{-1}$ at $\mathrm{PH}=13.8$ according to the previous literature. ${ }^{1-3}$ According to the CL spectrum and kinetic curves, the CL QYs were calculated according to the following equations: $\phi_{C L}=\frac{\mathrm{Q} \times f_{\text {luc }} \times f_{\text {photo }}}{n_{\mathrm{CPPO}}}($ einsteins $/ \mathrm{mol})$

$f_{l u c}=\frac{\phi_{l u c} \times n_{l u c}}{Q_{l u c}}$

$f_{\text {photo }}=\frac{f\left(\lambda_{s}\right)}{f\left(\lambda_{\text {luc }}\right)}$

Where $\Phi_{\mathrm{CL}}$ is the CL QYs of the CDs, Q is the total light emission obtained by integration of emission intensity under time curves. $f_{\text {luc }}$ is obtained by measuring the emission kinetics of lucigenin reaction performed in standard conditions. $f_{\text {photon }}$ is obtained from the sensitivity at the emission wavelength $\left(\lambda=450 \mathrm{~nm}, f_{\text {iuc }}\right.$ of the lucigenin standard, and the corresponding emission of the CDs $\left(\lambda=450 \mathrm{~nm}, f_{\mathrm{CDs}}\right), \mathrm{n}$ is the number of moles of lucigenin $\left(n_{\text {luc }}\right)$ or the number of moles of CPPO $\left(n_{\mathrm{CPPO}}\right)$. Herein, $1-\mathrm{mL}$ different kinds of CDs ethanol solution $\left(1 \mathrm{mg} \mathrm{mL}^{-1}\right)$ were added into the mixture of $0.5-\mathrm{mL}$ CPPO solution $(20 \mathrm{mM})$ and $0.5-\mathrm{mL} \mathrm{H}_{2} \mathrm{O}_{2}$ solution $(0.2 \mathrm{M})$. Then the CL intensity was continuously measured by the wavelength-time mode of Hitach F-7000 spectrometer.

DFT Computational details. Spin-polarized density functional theory calculations were performed using CASTEP package with the Perdew-Burke-Ernzerhof (PBE) generalized gradient approximation (GGA) exchange-correlation functional. The pure graphene, various $\mathrm{N}$-doped graphene and $\beta-\mathrm{C}_{3} \mathrm{~N}_{4}$ layers have been studied comparatively, and all the atoms were allowed to relax in the calculations. The 
Ultrosoft Pseudopotentials were used to describe the ionic core electrons, and a plane-wave basis set with a cutoff energy of $300 \mathrm{eV}$ was adopted to treat the valence electrons. A threshold of self-consistent-field energy convergence was $1 \times 10^{-5}$ $\mathrm{eV} / \mathrm{atom}$, and the maximum force and displacement of the convergence criterion for the structural optimizations were set to $0.05 \mathrm{eV} / \AA$ and $0.002 \AA$, respectively. The Monkhorst-Pack k-point sampling was generated with a $2 \times 2 \times 1$ grid.

CL biosensor. In this work, H-NCD powder was dissolved in PBS for living experiment. For living cell fluorescence imaging experiments, cultured HeLa cells grown in a laboratory-built incubator were stained with H-NCDs $\left(50 \mu \mathrm{g} \mathrm{mL}^{-1}\right)$ in culture medium for $4 \mathrm{~h}$ at $37^{\circ} \mathrm{C}$ and then rinsed with ultrapure water for three times for using. For the CL imaging of in vitro cells experiments, 1-mL different concentration $(0,50,100,200$ and $400 \mu \mathrm{M})$ of $\mathrm{H}_{2} \mathrm{O}_{2}$ to irritate the cells and then rinsed with ultrapure water for several times to remove the $\mathrm{H}_{2} \mathrm{O}_{2}$. Then, the samples were added into $100-\mu \mathrm{L}$ mixture of $10-\mathrm{mg} \mathrm{mL}^{-1} \mathrm{CPPO}$, which is cross-linked with F127 to improve the hydrophilicity of CPPO. And immediately the CL imaging was acquired for $300 \mathrm{~s}$ with open filter using an IVIS imaging system. After CL imaging, the PL imaging was acquired for $1 \mathrm{~s}$ with open filter of emission at $540 \mathrm{~nm}$ with 420 nm excitation.

Cell viability measurement. For the cell viability measurement, the PBS solution with different concentrations $(0,0.16,0.8,4,20,100$ and $500 \mu \mathrm{M})$ of H-NCDs were used for incubating the HeLa cells for $24 \mathrm{~h}$ at $37{ }^{\circ} \mathrm{C}$. Then, the cell viability of HeLa cells was tested using standard MTT method for assessing the cytotoxicity of the H-NCDs. 

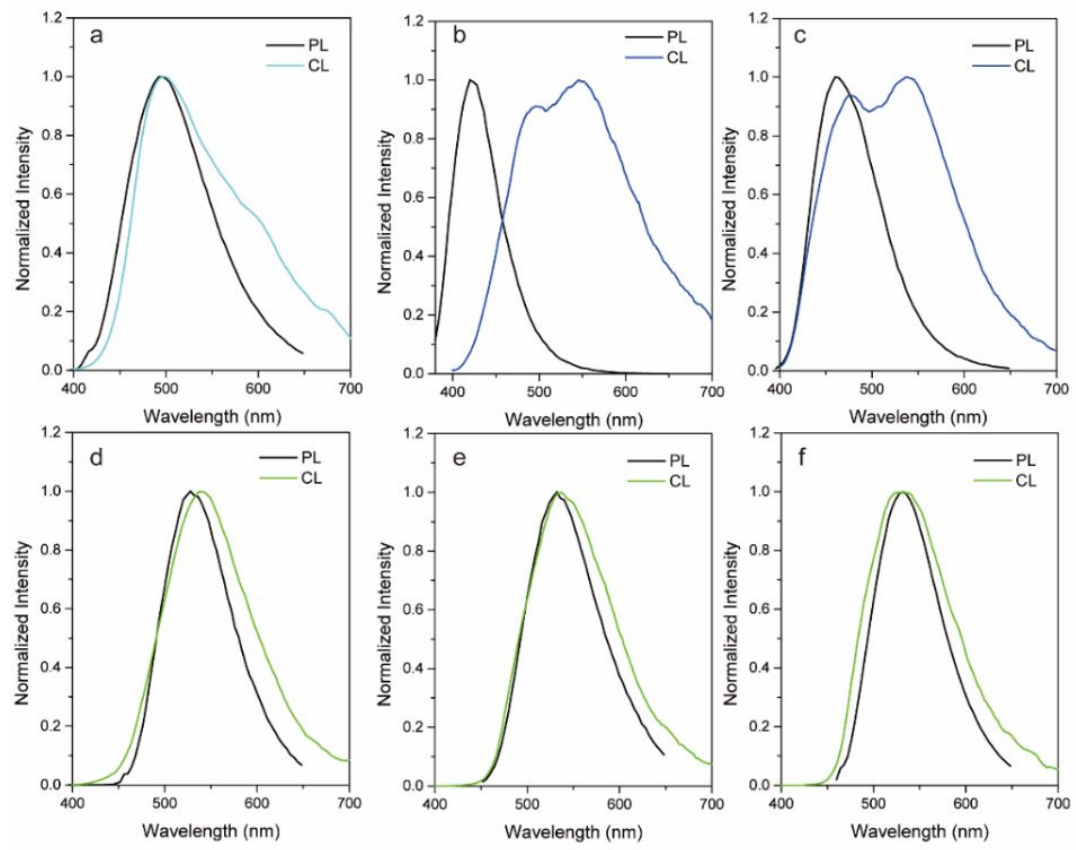

Figure S1. The normalized PL and CL spectra of the CDs synthesized by $0 \mathrm{~g}$ urea (a), $0.1 \mathrm{~g}$ urea (b), $0.4 \mathrm{~g}$ urea (c), $0.8 \mathrm{~g}$ urea (d), $1.6 \mathrm{~g}$ urea (e) and $2.4 \mathrm{~g}$ urea (f), respectively. 


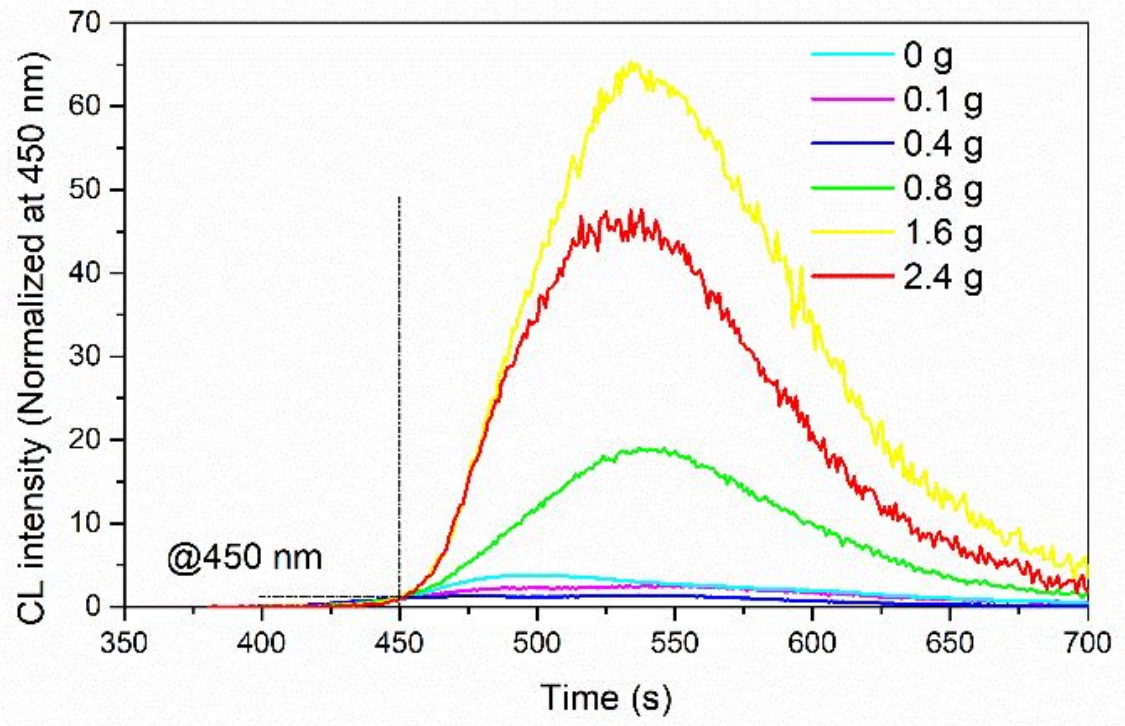

Figure S2. The normalized CL spectra at $450 \mathrm{~nm}$ of the different CDs. 

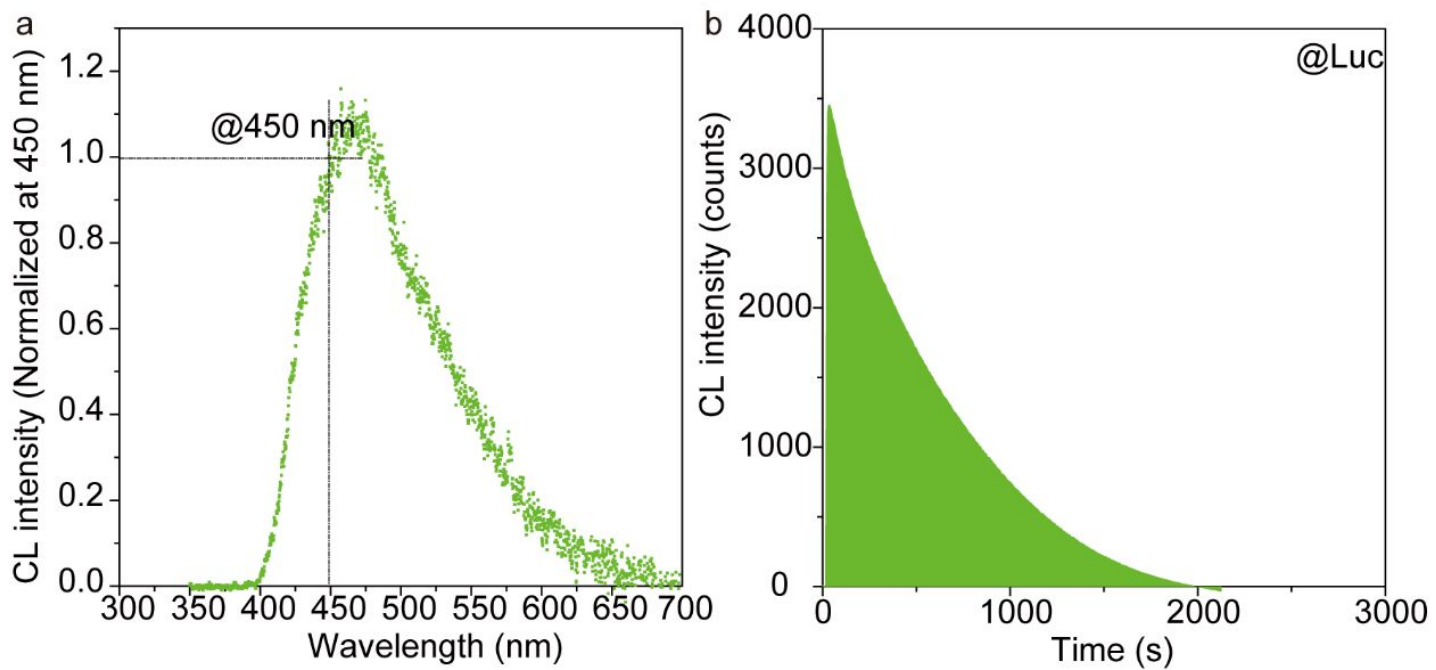

Figure S3. The normalized CL spectrum at $450 \mathrm{~nm}$ of the lucigenin with $\mathrm{H}_{2} \mathrm{O}_{2}$ (a) and the CL intensity decay at $450 \mathrm{~nm}$ (b). 


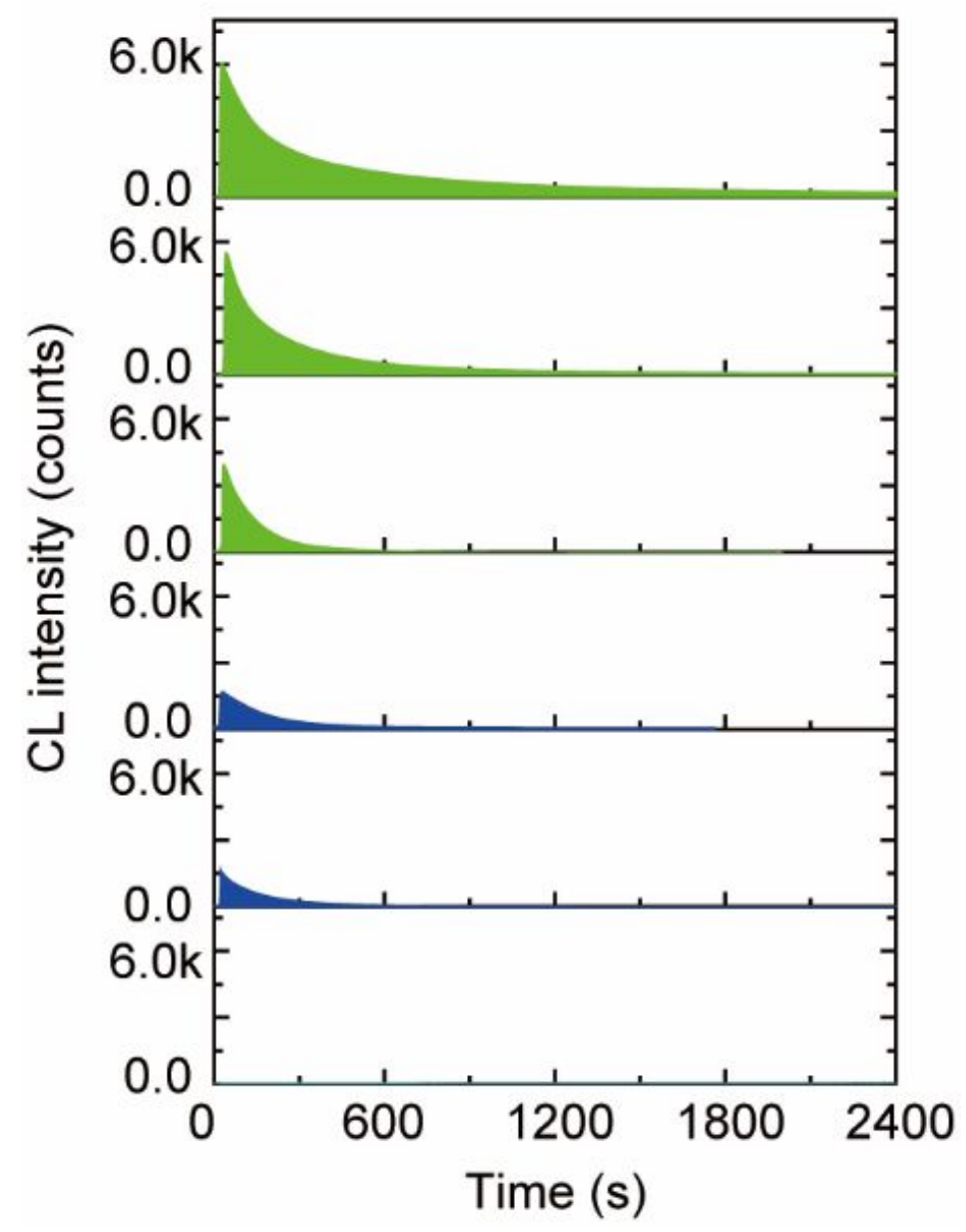

Figure S4. The CL intensity decay with different CDs as emitting species. 


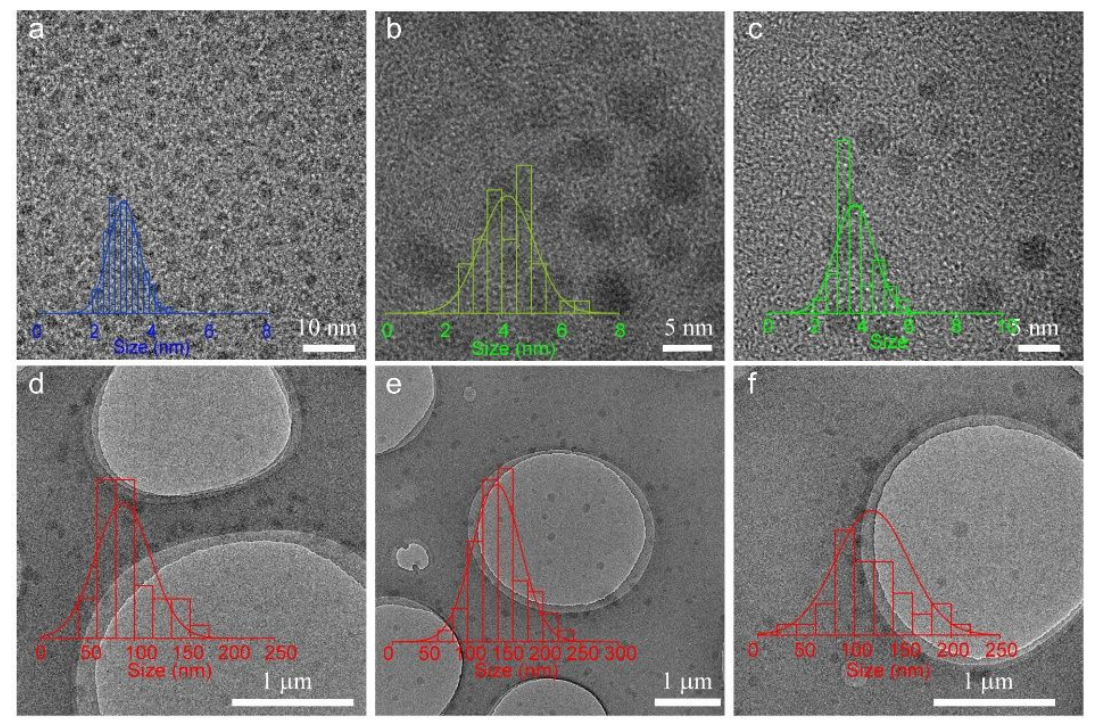

Figure S5. The TEM images of the CDs synthesized by 0.8-g citric acid and 0-g (a), 0.1-g (b), 0.4-g (c), 0.8-g (d), 1.6-g (e) and 2.4-g urea (f), respectively. 

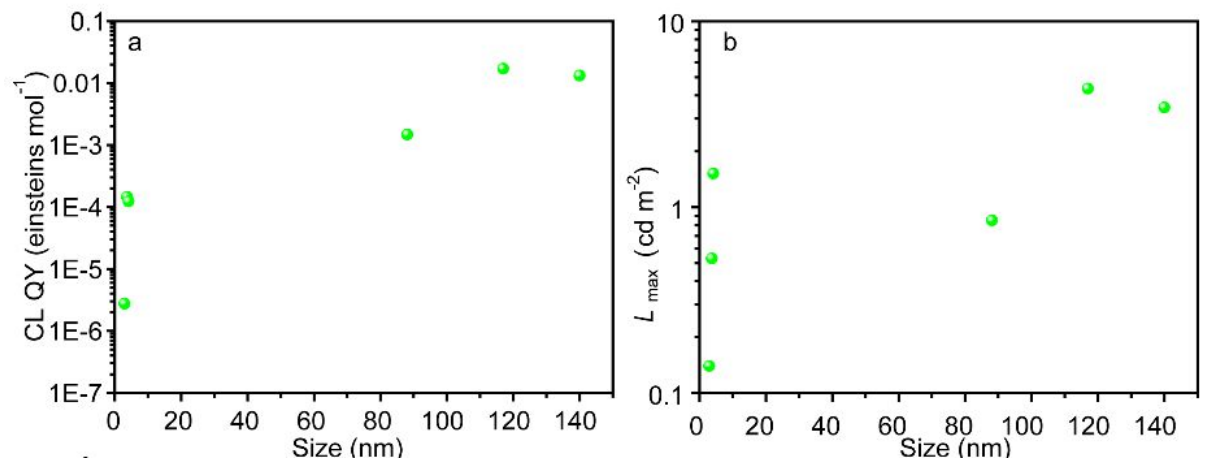

Figure S6. The relationships between the CL QY (a) and $L_{\max }(\mathrm{b})$ and their size of CDs. 


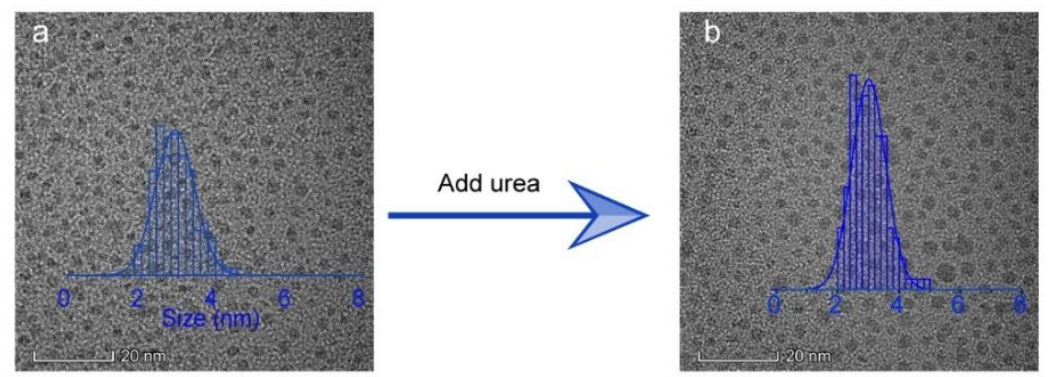

Figure S7. The TEM images of the OCDs without and with the addition of urea. 
a

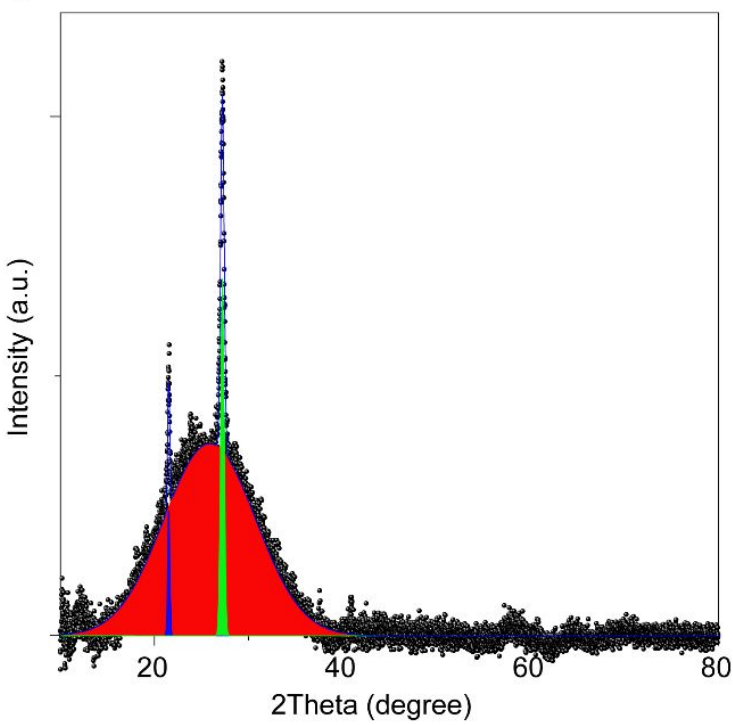

b Model Gauss

Equation $\mathrm{y}=\mathrm{y} 0+\left(\mathrm{A} /\left(\mathrm{w}^{*} \mathrm{sqrt}(\mathrm{PI} / 2)\right)\right)^{*} \exp \left(-2^{*}((\mathrm{x}-\mathrm{xc}) / \mathrm{w})^{\wedge} 2\right)$ Reduced Chi-Sqr $\quad 4.04768 \mathrm{E}-4$

Adj. R-Square 0.97832

Value Standard Eror

$\begin{array}{llll}\text { Peak1(E) y0 } & -0.00127 & 3.02501 \mathrm{E}-4\end{array}$

$\begin{array}{llll}\text { Peakl(E) } \quad \mathrm{xc} & 21.52464 & 0.00286\end{array}$

$\begin{array}{llll}\text { Peak1(E) W } & 0.22628 & 0.00581\end{array}$

Peak1(E) A $0.07127 \quad 0.00163$

Peakl(E) sigma $0.11314 \quad 0.00291$

$\begin{array}{llll}\text { Peak1(E) FWHM } \quad 0.26642 & 0.00684\end{array}$

Peakl(E) Height $0.25132 \quad 0.00553$

$\begin{array}{llll}\text { Peak2(E) } \quad \text { y0 } & -0.00127 & 3.02501 \mathrm{E}-4\end{array}$

Peak2(E) xc $25.8876 \quad 0.0132$

$\begin{array}{llll}\text { Peak2(E) } & \text { W } & 9.75639 & 0.02848\end{array}$

$\begin{array}{llll}\text { Peak2(E) } & \text { A } & 4.53148 & 0.01316\end{array}$

Peak2(E) sigma 4.87820 .01424

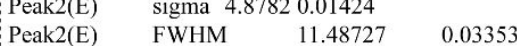

Peak2(E) Height $0.37059 \quad 9.352 \mathrm{E}-4$

Peak3(E) y0 $\quad-0.00127 \quad 3.02501 E-4$

$\begin{array}{lll}\text { Peak3(E) } \quad \mathrm{xc} & 27.23414 & 0.00134\end{array}$

$\begin{array}{llll}\text { Peak3(E) W } & 0.37573 & 0.00277\end{array}$

$\begin{array}{llll}\text { Peak3(E) A } & 0.32447 & 0.0022\end{array}$

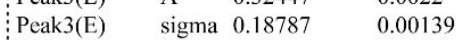

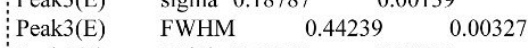

Peak3(E) Height $0.68902 \quad 0.00432$

Figure S8. The XRD (a) and corresponding fitted results (b) of H-NCDs. 

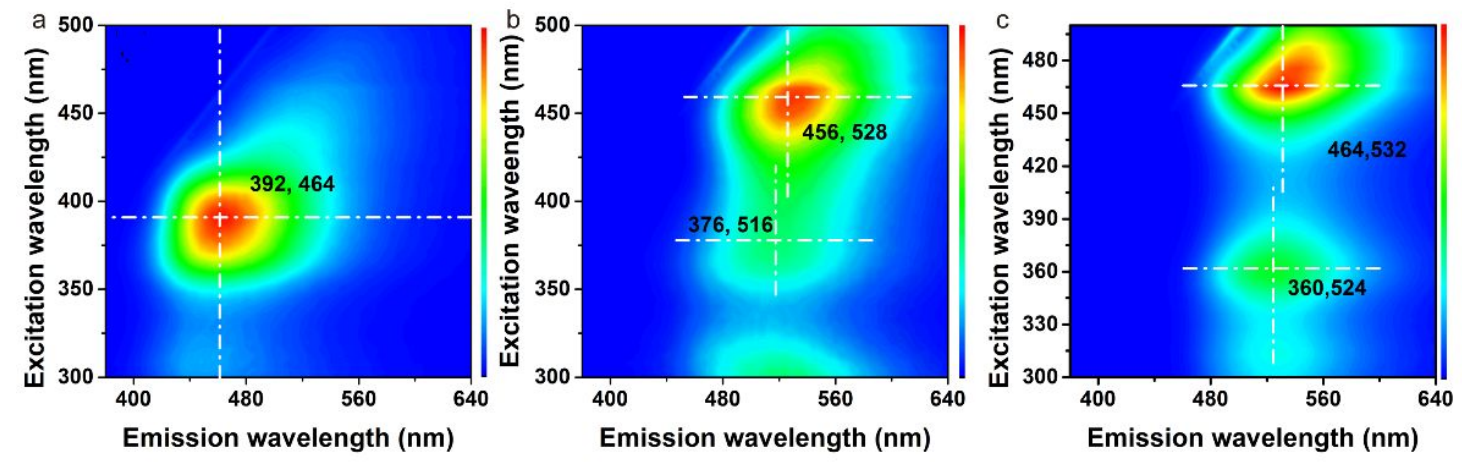

Figure S9. The excitation-emission matrix of the CDs synthesized by $0.8 \mathrm{~g}$ citric acid and $0.4 \mathrm{~g}$ urea (a), $0.8 \mathrm{~g}$ urea (b) and $2.4 \mathrm{~g}$ urea (c), respectively. 

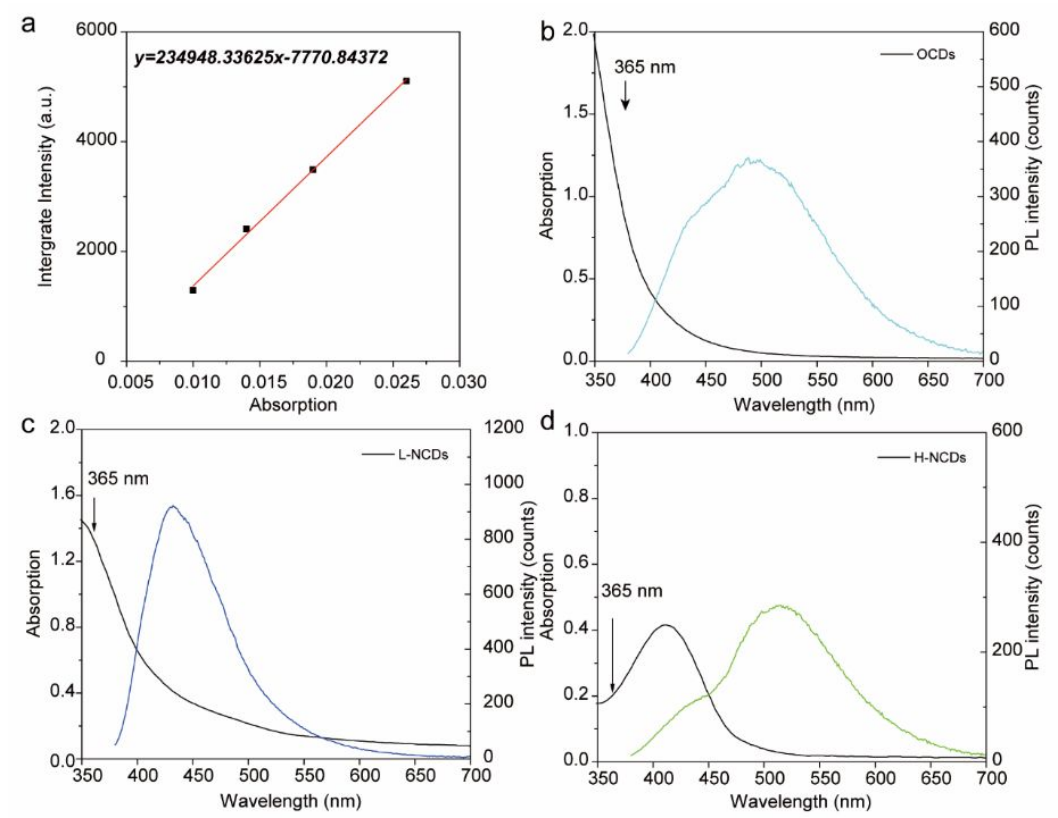

Figure S10. Calculated PL QY with $\mathrm{RhB}$ as reference: the absorption vs integrated PL intensity of RhB (a), the absorption spectra and corresponding PL spectra of OCDs (b), L-NCDs (c) and H-NCDs (d). 

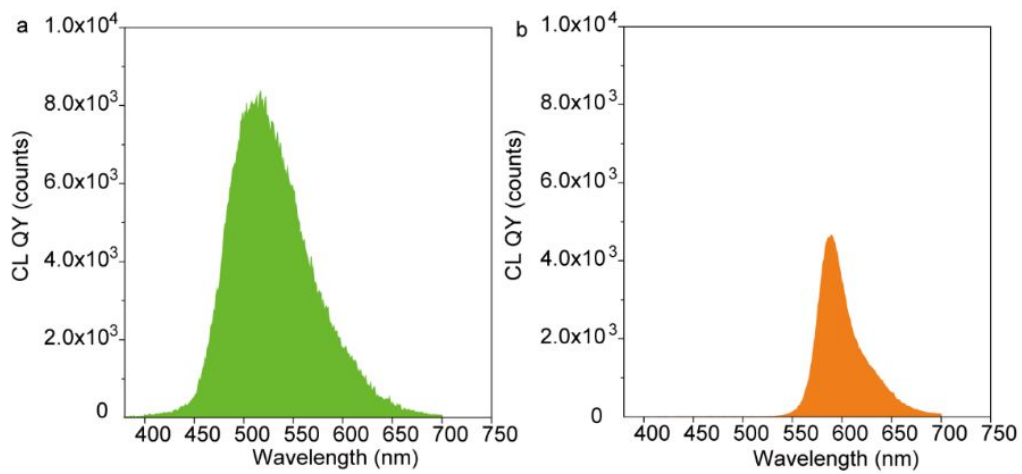

Figure S11. The CL spectra of the H-NCDs and RhB in the chemical illumination. 

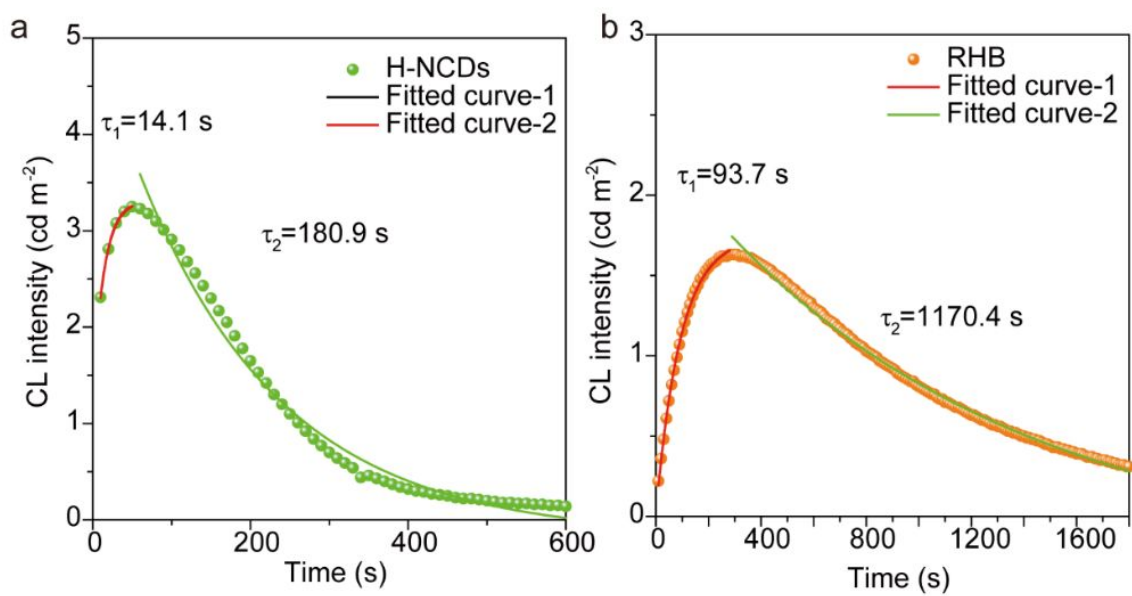

Figure S12. The CL lifetime of the H-NCDs and $\mathrm{RhB}$ in the chemical illumination.

Note: The HOMO levels of the CDs were measured by the valence band XPS. ${ }^{4,5}$ The valence band potentials $\left(\mathrm{E}_{\mathrm{HOMO}}{ }^{\mathrm{NHE}}\right)$ of the three CDs were obtained through fitting the cut-off edge of the low-energy XPS. The obtained $\mathrm{E}_{\mathrm{HOMO}} \mathrm{NHE}$ is the VB potential vs. NHE. As the NHE is equal to $-4.5 \mathrm{eV}$, so $\mathrm{E}_{\mathrm{HOMO}}$ $=-\mathrm{E}_{\mathrm{HOMO}}{ }^{\mathrm{NHE}}-4.5 \mathrm{eV}$. In this work, the $\mathrm{E}_{\mathrm{VB}}$ of the CDs could be fitted with the valence band XPS data. With the energy level of HOMO, the energy level of LUMO could be calculated with $\mathrm{E}_{\mathrm{LUMO}}=\mathrm{E}_{\mathrm{HOMO}}+\mathrm{E}_{\mathrm{g}}$. 


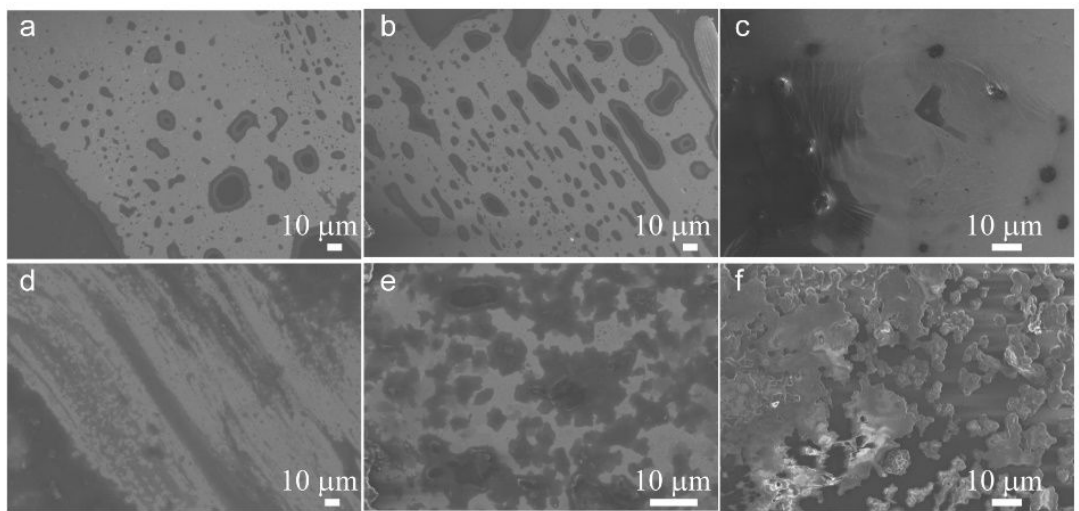

Figure S13. The SEM images of the CDs synthesized by 0.8-g citric acid and 0-g (a), 0.1-g (b), 0.4-g (c), 0.8-g (d), 1.6-g (e) and 2.4-g urea (f) at low magnifications, respectively.

Note: The SEM images of CDs have been measured on the silicon wafer, as shown in Figure S13, in which the black spots are the agglomerate of the individual CDs. Due to the aggregation and low electrical conductivity of CDs, the SEM images usually suffer from the low resolution and can provide rare information about the CDs. Hence, they are rarely used for the characterization of CDs. 
Table S1. The detailed comparison of the CL CDs with other previous reports.

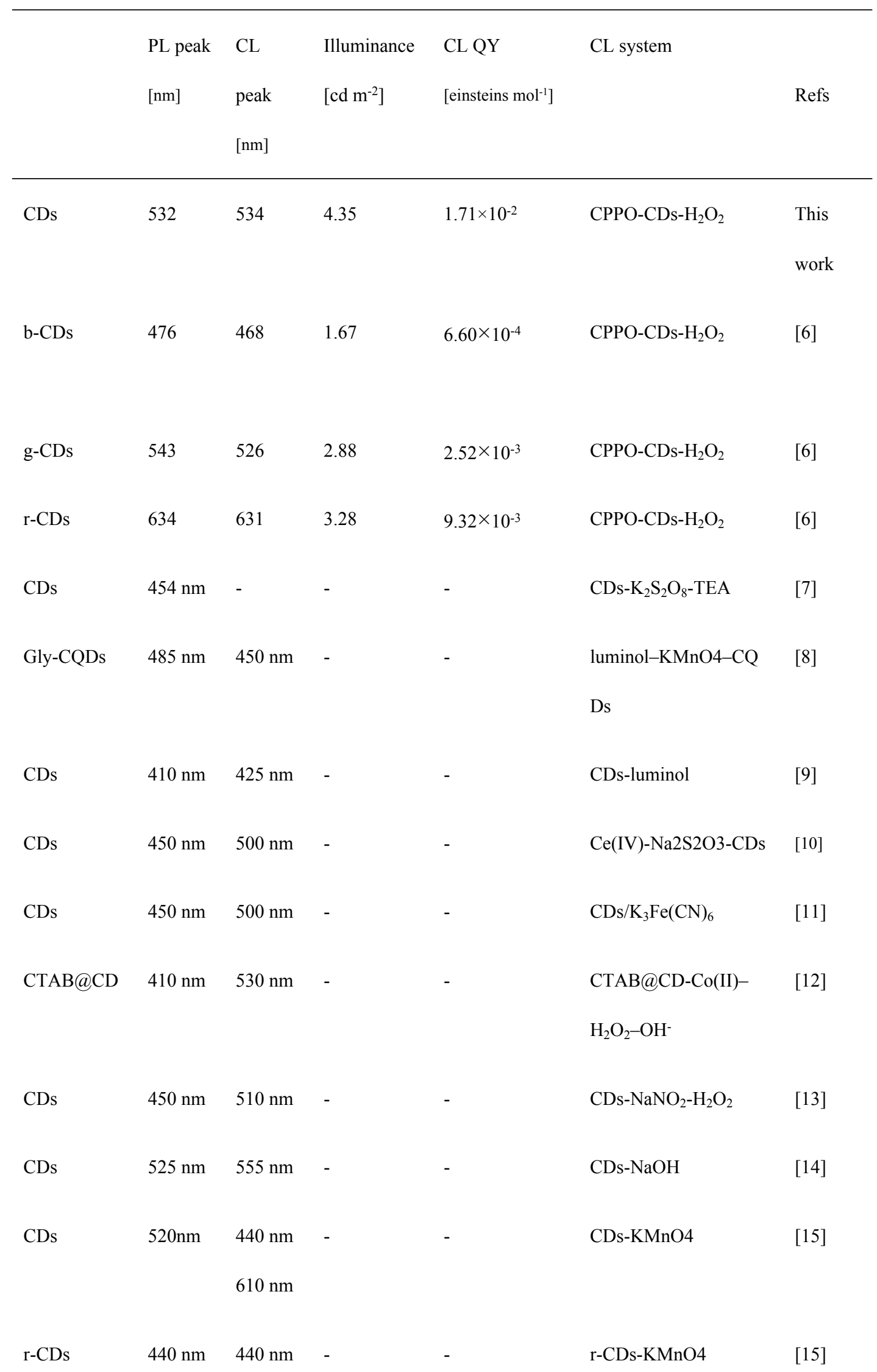




\begin{tabular}{|c|c|c|c|c|c|c|}
\hline CDs & $360 \mathrm{~nm}$ & $490 \mathrm{~nm}$ & - & - & $\mathrm{CDs}-\mathrm{H}_{2} \mathrm{O}_{2}-\mathrm{HSO}_{3}$ & {$[16]$} \\
\hline \multirow[t]{2}{*}{$\mathrm{CDs}$} & $450 \mathrm{~nm}$ & $500 \mathrm{~nm}$ & - & - & $\mathrm{CDs}-\mathrm{KMnO} 4$ & {$[17]$} \\
\hline & & $650 \mathrm{~nm}$ & & & & \\
\hline CDs & $450 \mathrm{~nm}$ & $500 \mathrm{~nm}$ & - & - & CDs-cerium(IV) & {$[17]$} \\
\hline $\mathrm{Au}$ NPs & $415 \mathrm{~nm}$ & $415 \mathrm{~nm}$ & - & $(2.8 \pm 0.3) \times 10^{-5}$ & $\mathrm{Au}$ NPs-TCPO- $\mathrm{H}_{2} \mathrm{O}_{2}$ & {$[18]$} \\
\hline \multirow[t]{3}{*}{$\mathrm{Au}$ NPs } & $415 \mathrm{~nm}$ & $640 \mathrm{~nm}$ & - & - & Gold & [19] \\
\hline & & & & & colloids- $\mathrm{KMnO}_{4}-\mathrm{H}_{2} \mathrm{SO}$ & \\
\hline & & & & & 4 & \\
\hline \multirow[t]{2}{*}{$\mathrm{CdTe}$} & $550 \mathrm{~nm}$ & $540 \mathrm{~nm}$ & - & - & CdTe-Oxidation & {$[20]$} \\
\hline & $-580 \mathrm{~nm}$ & $-620 \mathrm{~nm}$ & & & & \\
\hline
\end{tabular}

\section{Reference}

[1] X. Zhen, C. Zhang, C. Xie, Q. Miao, K. L. Lim, K. Pu, ACS Nano 2016, 10, 6400.

[2] H. Cui, Z. Zhang, M. Shi, Y. Xu, Y. Wu, Anal. Chem. 2005, 77, 6402.

[3] D. Mao, W. Wu, S. Ji, C. Chen, F. Hu, D. Kong, D. Ding, B. Liu, Chem 2017, 3, 991.

[4] A. D. Fortes, E. Suard, K. S. Knight. Science 2011, 331, 742-6.

[5] Y. Wang, M. K. Bayazit, S. J. A. Moniz, Q.i Ruan, C. C. Lau, N. Martsinovich J.

Tang. Adv Energy Mater. 2018, 8, 1801084.

[6] C.L. Shen, Q. Lou, C. F. Lv, J. H. Zang, S. N. Qu, L. Dong, C. X. Shan. Adv. Sci. 2019, 1802331

[7] H. Zhang, X. Zhang, and S. Dong. Anal. Chem. 2015, 87, 11167.

[8] Z. Yan, Y. Yu, J. Chen, Anal. Methods 2015, 7, 1133.

[9] Y. Guo, B. Li, Carbon 2015, 82, 459. 
[10] M. Amjadi, J. L. Manzoori, T. Hallaj, M. H. Sorouraddin, Microchim. Acta 2014, 181,671 .

[11] M. Amjadi, J. L. Manzoori, T. Hallaj, M. H. Sorouraddin. Spectrochim.

Acta 2014, 122, 715.

[12] J. Shi, C. Lu, D. Yan, L. Ma, Biosens. Bioelectro. 2013, 45, 58.

[13] Z. Lin, W. Xue, H. Chen, J. Lin, Anal. Chem. 2011, 83, 8245.

[14] L. Zhao, F. Di, D. Wang, L. Guo, Y. Yang, B. Wan, H. Zhang, Nanoscale 2013, $5,2655$.

[15] P. Teng, J. Xie, Y. Long, X. Huang, R. Zhu, X. Wang, L. Liang, Y. Huang, H. Zheng, J. Lumin. 2014, 146, 464.

[16] W. Xue, Z. Lin, H. Chen, C. Lu, J. M. Lin. J. Phys. Chem. C 2011, 115, 21707.

[17] Z. Lin, W. Xue, H. Chen, J. Lin, Chem. Commun. 2012, 48, 1051.

[18] H. Cui, Z. Zhang, M. Shi, Y. Xu, Y. Wu, Anal. Chem. 2005, 77, 6402.

[19] Z. F. Zhang, H. Cui, M. J. Shi. Phys. Chem. Chem. Phys. 2006, 8, 1017.

[20] Z. Wang, J. Li, B. Liu, J. Hu, X. Yao. J. Phys. Chem. B 2005, 109, 23304. 